vol. $37-n^{\circ} 1$ et 2 | 2021

Travail et migrations

Terrazzoni Liza, Les Autres en Corse. Pour une sociologie des relations interethniques

\title{
Ralph Schor
}

\section{(2) OpenEdition}

10 Journals

Édition électronique

URL : https://journals.openedition.org/remi/18784

DOI : $10.4000 /$ remi. 18784

ISSN : $1777-5418$

Éditeur

Université de Poitiers

Édition imprimée

Pagination : 323-325

ISBN : 979-10-90426-69-6

ISSN : 0765-0752

Référence électronique

Ralph Schor, "Terrazzoni Liza, Les Autres en Corse. Pour une sociologie des relations interethniques », Revue européenne des migrations internationales [En ligne], vol. 37 - $n^{\circ} 1$ et 2 | 2021, mis en ligne le 25 novembre 2021, consulté le 16 mai 2022. URL : http://journals.openedition.org/remi/18784; DOI : https://doi.org/10.4000/remi.18784

Ce document a été généré automatiquement le 16 mai 2022.

(c) Université de Poitiers 


\title{
Terrazzoni Liza, Les Autres en Corse. Pour une sociologie des relations interethniques
}

\author{
Ralph Schor
}

\section{RÉFÉRENCE}

Terrazzoni, Liza, Les Autres en Corse. Pour une sociologie des relations interethniques. -

Ajaccio : Albiana, 2019. - 246 p. ISBN : 978-2-82410-938-1

1 La Corse est régulièrement le lieu d'affrontements de rue ou d'attentats visant les " autres", continentaux ou étrangers. Ces derniers, au sens juridique du terme, constituent environ $10 \%$ de la population depuis les années 1980. Les chefs du Front de libération nationale de la Corse (FLNC) estiment eux-mêmes avoir commis 10000 attentats et 220 assassinats entre 1976, date de la création du FLNC, et 2016, date de la «cessation des actions militaires». Liza Terrazzoni, sociologue à l'École des hautes études en sciences sociales, a effectué des enquêtes, dans les années 2000, pour comprendre les origines sociales, historiques et politiques de ces événements, en définir le sens, en mesurer la signification xénophobe ou raciste.

2 Liza Terrazzoni analyse d'abord l'importance de l'immigration maghrébine en Corse. En 1999, les Marocains forment $52 \%$ des effectifs étrangers dans l'île. Ils sont surreprésentés dans les emplois ouvriers. Les immigrés étant victimes d'une "violence physique régulière et répétée » (p. 37), l'auteur se demande si les attentats, meurtres, rackets, ne révèlent pas un racisme corse spécifique. Elle remarque que la violence s'est aussi exercée contre des Français continentaux et des touristes, que les agressions furent nombreuses dans tout l'hexagone au long des années 1980, que la violence constitue en Corse une action clé de l'ordre social et une pratique souvent «admise et normalisée » (p. 46) sous le nom de vendetta, de sorte que les Maghrébins ne sont pas forcément l'objet d'un racisme qui leur serait particulier. Cependant les slogans et 
graffitis «I Arabi fora ( (Les Arabes dehors») sont fréquents, les intéressés sont évincés de certains espaces publics, se disent souvent méprisés et menacés, notamment dans leurs tentatives d'ascension sociale. En somme, ils se sentent confinés dans la catégorie des autres face à la catégorie corse dont l'accès est étroitement fermé.

L'auteure insiste sur ce qu'elle considère comme une ethnicisation de la société corse. Elle souligne que les autochtones veulent se distinguer des Arabi ou Arabacci, le suffixe " acci» étant plus dépréciatif. Ceux-ci sont vus comme des envahisseurs particulièrement associés au trafic des stupéfiants. Quant aux Pinzutti, ce sont les Français du continent, incapables de comprendre la Corse, privilégiés, avares, individualistes, dépourvus de tout esprit collectif, artisans de l'invasion maghrébine. Liza Terrazzoni soutient que, face à ces autres, les Corses s'enferment dans une ethnicité comprise comme une construction sociale. Les fondements de la différence sont l'insularité, la langue très présente au quotidien, l'histoire, la perception d'une corsophobie attribuée aux autres, le jeu des appartenances ou affiliations familiales, villageoises, claniques. Ces liens doivent gouverner les rapports professionnels, amicaux, amoureux, ce qui exclut les étrangers qui ne peuvent espérer aucune solidarité. Ainsi, montre l'auteure, la société insulaire élabore une catégorisation et finalement une hiérarchie entre les Corses, situés au sommet, et les autres.

Liza Terrazzoni s'arrête longuement sur la dimension démo-historique de l'identité corse. Elle étudie le dépeuplement de l'île, facteur de stagnation économique, puis le redressement avec l'arrivée des pieds noirs, souvent accompagnés de leurs employés maghrébins, l'essor de l'agriculture, du bâtiment, du tourisme. Les changements et les aides attribuées par l'État français aux nouveaux venus sont ressentis dans l'île comme des signes d'inégalité, de dépossession, d'injustice. Ainsi, pour faire pièce à la discrimination dont ils s'estiment victimes, les Corses auraient renforcé l'image négative de l'étranger, fortifié leur propre réputation de peuple indomptable, traditionnel résistant contre ceux qui veulent l'insulter, le coloniser, altérer son particularisme. La figure du Sarrasin de jadis, agressif et pilleur, est revivifiée. Les Corses se considèrent eux-mêmes comme de "bons colonisateurs", car ils ont été contraints à l'expatriation pour cause de misère et ont peu participé à l'exploitation coloniale.

5 Le livre éclaire enfin les origines politiques de la distinction entre les Corses et les autres. À partir des années 1960, le sentiment que les insulaires constituent une minorité opprimée s'est banalisé, ce qui sert de terreau au nationalisme tourné contre les "privilégiés ", rapatriés et continentaux. Les événements d'Aléria en 1975 ont cimenté le rejet de l'État vu comme répressif et légitimé la violence développée par le FLNC, né l'année suivante. L'hebdomadaire Arritti assure : « La mort du peuple corse est planifiée » (3 septembre 1976). Jean-Guy Talamoni dénonce «la volonté des dirigeants français de faire disparaître notre peuple» (Journées internationales de Corte, 2008). Certains estiment que l'État organise un "génocide» des Corses par l'effet de l'immigration étrangère. Le facteur ethnique devient le cadre d'interprétation des problèmes de l'île. Dès lors, le nationalisme est considéré comme un acte de légitime défense contre les Maghrébins fanatiques et délinquants, donc comme un moyen de préserver l'ordre social.

6 L'auteure conclut que la société corse est aujourd'hui fortement ethnicisée. Le nationalisme mobilise moins de thèmes politiques qu'une valorisation de l'ethnicité corse. Cette conception entraîne l'exclusion des autres, privés d'accès à divers 
domaines de la vie publique. Ce sont l'exclusion brutale et la banalisation de la violence qui engendrent des pratiques racistes.

7 Liza Terrazzoni offre une étude fouillée et ouvre de nombreuses pistes de réflexion. Le lecteur aimerait que certaines de celles-ci soient davantage explorées. Ainsi pour les liens entre les idées du nationalisme corse et celles de l'extrême droite, seulement évoqués au détour d'une phrase. Il en va de même pour les connexions du nationalisme et du banditisme, illustrées par des faits et fondés sur une réflexion théorique. La démonstration semble admettre une diffusion générale d'un sentiment nationaliste exclusif, certes avec des degrés dans la manifestation de l'identité corse. On aurait apprécié que fût effectuée une étude d'opinion permettant de mesurer exactement le phénomène et de savoir de la sorte s'il est unanime ou non. Il n'en reste pas moins que l'auteure fait preuve d'une excellente connaissance du terrain, ce qui l'amène à rapporter souvent, à la première personne, des observations qu'elle a effectuées sur place. Les nombreux témoignages qu'elle transcrit offrent de précieux renseignements, une sorte de plongée dans la conscience et le vécu des témoins. Elle présente avec une grande honnêteté le résultat de ses recherches, sans complaisance pour aucune des parties en présence. Les situations passionnelles ont besoin de tels regards scientifiques.

\section{AUTEURS}

\section{RALPH SCHOR}

Historien, Professeur émérite

Université Côte-d'Azur/CMMC 